\title{
Pre-frailty and frailty of elderly residents in a municipality with a low Human Development Index
}

\author{
Wanderley Matos Reis Júnior ${ }^{1}$ \\ José Ailton Oliveira Carneiro ${ }^{2}$ \\ Raildo da Silva Coqueiro ${ }^{3}$ \\ Kleyton Trindade Santos ${ }^{4}$ \\ Marcos Henrique Fernandes ${ }^{2}$
}

\begin{abstract}
Objective: to identify the prevalence of the factors associated with pre-frailty and frailty of elderly residents in a municipality with a low Human Development Index Method: Cross-sectional study with a populational and household framework conducted with 316 elderly people. Frailty was determined from the presence of three or more of the following factors: (i) self-reported unintentional weight loss; (ii) lack of strength and energy; (iii) weakness; (iv) slowness; (v) low level of physical activity. The association between frailty and socio-demographic, behavioral and health factors was measured using the multinomial logistic regression technique. Results: The prevalence of pre-frailty and frailty was $58.7 \%$ and $23.8 \%$, respectively. The adjusted regression model showed that the state of pre-frailty was associated with gender, age group and BMI, and frailty was associated with gender, age group, hospitalization, functional capacity, and self-perceived health. Conclusion: The evidence presented in this study demonstrates more variables associated with the frailty condition, reinforcing the concept of a multifactorial clinical syndrome that may result in the loss of functionality.
\end{abstract}

Descriptors: Aging; Frail Elderly; Health Status.

\footnotetext{
${ }^{1}$ MSc, Assistant Professor, Departamento de Saúde, Universidade Estadual do Sudoeste da Bahia, Jequié, BA, Brazil.

${ }^{2}$ PhD, Adjunct Professor, Departamento de Saúde, Universidade Estadual do Sudoeste da Bahia, Jequié, BA, Brazil.

${ }^{3}$ Doctoral student, Universidade Federal da Bahia, Salvador, BA, Brazil. Assistant Professor, Universidade Estadual do Sudoeste da Bahia, Jequié, BA, Brazil.

${ }^{4}$ Master's student, Universidade Estadual do Sudoeste da Bahia, Jequié, BA, Brazil.
} 


\section{Introduction}

The aging process brings changes, which together with the increased prevalence of chronic diseases can cause the onset of geriatric syndromes, among which the frailty syndrome is highlighted. Frailty includes factors of different orders, being characterized as a syndrome resulting from the loss of physiological reserves and adaptation to stressors, where the energy deficit, sarcopenia, decreases the muscle strength and tolerance to effort leading to an exacerbated decline in multiple systems that places the individual in a condition of greater vulnerability ${ }^{(1)}$.

Frailty has increasingly emerged as an important concept, both in the clinical care of older people, as well as in studies on aging. As a clinical syndrome, it is usually associated with an increased risk of adverse situations such as falls, disabilities, institutionalization, and death ${ }^{(2)}$. There is no defined scientific consensus regarding the term frailty, its definition and its indicators, nor how it can be identified or even evaluated. However, the majority of studies that deal with frailty generally define it as an unstable condition related to functional decline, from the interaction of the individual with the environment, in which, an event considered of minor impact can cause limitations in the performance of voluntary activities and result in the loss of autonomy and functional capacity(3).

The reversal of the installation of advanced frailty frameworks may be linked to the identification of factors that are considered open to modifications, such as socioeconomic conditions, lifestyle, and social support, in which the early identification of signs and symptoms causing the frailty syndrome may indicate the adoption of objective interventions that prevent complications of the frailty and injuries in the elderly population(4).

In Brazil, the majority of municipalities experience an increase in the number of elderly in the population each year. They present poor health indicators and this may contribute to the development of early frailty resulting in an unfavorable prognosis with dependence, hospitalization and severe complications in the subsequent years ${ }^{(4)}$. In addition, research into the identification of frailty in the elderly is at an early stage, therefore there are few population-based studies that present factors involved in the process of frailty in the Brazilian population.

When studying frailty it is essential to consider the context in which this process takes place. Since
Brazil is a country of continental dimensions it is essential to understand how frailty develops in regions marked by pronounced social inequalities. Thus, the aim of this study was to identify the prevalence and the factors associated with pre-frailty and frailty of elderly residents in a community with a low human development index.

\section{Method}

This is a cross-sectional study that is part of epidemiological study with a community and populational basis, the title of which is: Nutritional status, risk behaviors and health conditions of the elderly people of Lafaiete Coutinho-BA. A census was conducted in January 2011 with elderly people residing in urban areas, registered in the Family Health Strategy, which achieves $100 \%$ coverage. All those aged $\geq 60$ years $(n=355)$ were contacted for interviews and to carry out examinations (blood tests, arterial pressure measurement, anthropometric measures, and motor tests). Of the 355 elderly people, 316 participated in the study $(89.0 \%)$. There were 17 refusals $(4.8 \%)$ and $22(6.2 \%)$ individuals were not located in their residences after three visits at different times.

A specific form was used, based on the questionnaire used in the Health, Welfare and Aging Study SABE (http://hygeia.fsp.usp.br/sabe/quetionario.php), conducted in seven countries in Latin America and the Caribbean(5), with the International Physical Activity Questionnaire (IPAQ)(6), adapted for the elderly(7) added to this, as well as the Geriatric Depression Scale (GDS), used for screening for depression in the elderly and consisting of 15 questions with yes or no answers, also having been validated for use in Brazil(8).

Frailty (dependent variable) was identified according to the modified version of frailty, considering

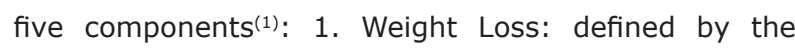
self-report of unintentional weight loss of $\geq 3 \mathrm{~kg}$ during the 12 months preceding the study ${ }^{(9)}$, as the instrument used was based on the SABE study, which does not make an objective prediction for weight loss. 2. Muscle weakness: Manual Gripping Force (MGF) was evaluated by means of a hydraulic dynamometer (Saehan Corporation SH5001, Korea). Frailty was defined according to the gender and body mass index (BMI). For each category, the cutoff points for the MGF (Kgf) were fixed in the 25th percentile, with adjustments for gender and BMI. The cutoff points for men adopted 
were: $0<\mathrm{BMI}<22$ - MGF $\leq 19 \mathrm{Kgf}$; $22 \leq \mathrm{BMI} \leq 27$ $M G F \leq 21 \mathrm{Kgf} ., \mathrm{BMI}>27$ - MGF $\leq 22 \mathrm{Kgf}$; and for women: $0<B M I<22$ - MGF $\leq 11$ Kgf.; $22 \leq B M I<27$ - MGF $\leq 15 \mathrm{Kgf}$., $B M I>27-M G F \leq 14 K g f$. 3. Low resistance and energy: defined based on two questions of the $\operatorname{GDS}^{(8)}$ : "Have you put aside many of your activities and interests?" and "Do you feel full of energy?". A positive answer to the first question and/or a negative answer to the second were considered evidence of low resistance/lack of energy. 4. Slowness in the walking test: defined through the physical performance of a $2.44 \mathrm{~m}$ walking test. The slowness was adjusted according to the gender and height of the elderly person. The height was divided into two categories based on the median ( $50^{\text {th }}$ percentile) men $\leq 1.61 \mathrm{~m}$ and women $\leq 1.49 \mathrm{~m}$, below or equal to the median; men $>1.61 \mathrm{~m}$ and women $>1.49 \mathrm{~m}$, above the median. For each category the cutoff points that considered the individual slow in the walking test were fixed in the $75^{\text {th }}$ percentile: below or equal to the median, $\geq 5 \mathrm{~s}$ and $\geq 6 \mathrm{~s}$ (for men and women, respectively); above the median, $\geq 4 \mathrm{~s}$ (for both genders). Low level of physical activity: The instrument used to evaluate the level of habitual physical activity was the International Physical Activity Questionnaire (IPAQ) ${ }^{(7)}$. The individuals who performed less than 150 minutes per week of moderate and/or vigorous physical activity were considered insufficiently active.

An ordinal variable with scores ranging from zero to five (0-5) was created from the sum of the points of all the components, with the following classification adopted: 0 points $=$ not frail; $1-2$ points = pre-frail; $\geq 3$ points $=$ frail $^{(1)}$. All the individuals who responded to only 3 components and that were classified as frail were considered. Individuals who answered at least 4 components for the classification of frailty were considered eligible for the other classifications $^{(9)}$. Thus, 286 subjects, classified according to frailty phenotype, were included in the analysis.

The explanatory variables were: 1. Sociodemographic: Gender, Age group, Knowledge of how to read and write a message, Family arrangement, Participation in religious activity. 2. Behavioral: Consumption of alcoholic beverage, and Use of tobacco. 3. Health conditions: Hospitalization in the previous year, Body Mass Index BMI: $\left(B M I<22 \mathrm{~kg} / \mathrm{m}^{2}=\right.$ underweight, $22 \mathrm{~kg} / \mathrm{m}^{2} \leq \mathrm{BMI} \leq 27 \mathrm{~kg} / \mathrm{m}^{2}$ = appropriate,

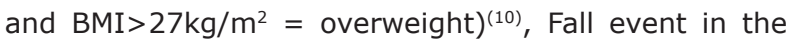
previous year, Number of self-reported chronic diseases, and Functional capacity (measured through the Basic Activities of Daily Living (BADL) using the Katz scale(11) and Instrumental Activities of Daily Living (IADL), using the Lawton scale(12)).

Amount of medications used, Self-perceived health, and Cognitive status (assessed through the Mini-Mental State Examination questionnaire. using the validated a modified version ${ }^{(13)}$ to verify the reliability of the answers - score $>12=$ not compromised and score $\leq 12=$ compromised). When the cognitive status score was not reached, the informant was asked to responded to another instrument, which was the Functional Activities questionnaire of Pfeffer ${ }^{(14)}$, with information pertaining to the elderly person, thus evaluating the need for a substitute informant during the interview.

The associations between frailty and the explanatory variables were verified by obtaining crude and adjusted estimates of the odds ratio, using a confidence interval of $95 \%$, through a multinomial logistic regression model. Variables that showed statistical significance of at least $20 \%(p \leq 0.20)$ in the crude analysis were included in the adjusted analysis, following the order of a hierarchical model for the determination of the outcomes ${ }^{(15)}$.

According to the model established, the variables of the upper levels (distal) interact among themselves and determine the variables of the lower levels (proximal). Regarding the effect of each explanatory variable on the outcome, the variables of the same level and upper levels in the model were controlled for, with the statistical criterion for remaining in the model being $20 \%(\mathrm{p} \leq 0.20)$.

The study was approved by the Research Ethics Committee of the State University of Southwest Bahia (no 064/2010). Data were tabulated and analyzed using the Statistical Package for the Social Sciences for Windows (SPSS ${ }^{\circledR}$ ), version 16.0 program.

\section{Results}

The prevalence of pre-frailty and frailty of the elderly people living in the urban area of the municipality of Lafaiete Coutinho-BA was 57.8 and $23.8 \%$, respectively.

Table 1 shows the crude analysis of the independent variables that composed the socio-demographic, behavioral, and health condition factors and their association with frailty in elderly people. 
Table 1 - Association between sociodemographic, behavioral, and health condition factors and pre-frailty and frailty in elderly people living in the community. Lafaiete Coutinho, BA, Brazil, 2011

\begin{tabular}{|c|c|c|c|c|c|c|c|}
\hline \multirow{2}{*}{ Variables } & \multicolumn{3}{|c|}{ Frail } & \multicolumn{3}{|c|}{ Pre-frail } & \multirow{2}{*}{$p$-value } \\
\hline & $\mathbf{n}$ & $\%$ & $\mathrm{OR}_{\text {crude }}(\mathrm{Cl} 95 \%)$ & $\mathbf{n}$ & $\%$ & $\mathrm{OR}_{\text {crude }}(\mathrm{Cl} 95 \%)$ & \\
\hline Gender & & & & & & & 0.002 \\
\hline Male & 31 & 23.7 & 1 & 66 & 50.4 & 1 & \\
\hline Female & 37 & 23.9 & $2.53(1.18-5.43)$ & 102 & 65.8 & $3.28(1.68-6.41)$ & \\
\hline Age group & & & & & & & $<0.001$ \\
\hline $60-69$ years & 16 & 14.7 & 1 & 66 & 60.6 & 1 & \\
\hline $70-79$ years & 19 & 19.0 & $1.78(0.72-4.35)$ & 63 & 63.0 & $1.43(0.71-2.85)$ & \\
\hline$\geq 80$ years & 33 & 42.9 & $11.13(3.61-34.32)$ & 39 & 50.6 & $3.19(1.13-8.96)$ & \\
\hline Knows how to read and write a message & & & & & & & 0.029 \\
\hline Yes & 18 & 18.0 & 1 & 57 & 57.0 & 1 & \\
\hline No & 50 & 26.9 & $2.77(1.28-6.01)$ & 111 & 59.7 & $1.94(1.02-3.69)$ & \\
\hline Family arrangement & & & & & & & 0.450 \\
\hline Accompanied & 54 & 22.6 & 1 & 141 & 59.0 & 1 & \\
\hline Alone & 14 & 29.8 & $1.90(0.67-5.35)$ & 27 & 57.4 & $1.40(0.54-3.62)$ & \\
\hline Religious activity & & & & & & & 0.952 \\
\hline Participants & 63 & 23.7 & 1 & 156 & 58.6 & 1 & \\
\hline Does not participate & 5 & 25 & $1.24(0.28-5.46)$ & 12 & 60 & $1.20(0.32-4.45)$ & \\
\hline Alcohol consumption & & & & & & & 0.329 \\
\hline Does not consume & 64 & 24.7 & 1 & 152 & 58.7 & 1 & \\
\hline Consumes & 4 & 14.8 & $0.38(0.10-1.39)$ & 16 & 59.3 & $0.64(0.25-1.67)$ & \\
\hline Use of tobacco & & & & & & & 0.249 \\
\hline Never smoked & 20 & 17.2 & 1 & 73 & 62.9 & 1 & \\
\hline Ex-smoker & 39 & 28.5 & $1.95(0.88-4.29)$ & 75 & 54.7 & $1.02(0.53-1.99)$ & \\
\hline Currently smokes & 9 & 27.3 & $2.58(0.69-9.70)$ & 20 & 60.6 & $1.57(0.48-5.08)$ & \\
\hline Hospitalization in the previous year & & & & & & & 0.003 \\
\hline No & 41 & 19.0 & 1 & 132 & 61.1 & 1 & \\
\hline One or more times & 27 & 38.6 & $4.04(1.58-10.30)$ & 36 & 51.4 & $1.67(0.69-4.03)$ & \\
\hline Body Mass Index & & & & & & & 0.006 \\
\hline Appropriate & 34 & 26.8 & 1 & 64 & 50.4 & 1 & \\
\hline Overweight & 10 & 12.5 & $0.65(0.25-1.71)$ & 57 & 71.3 & $1.98(0.94-418)$ & \\
\hline Underweight & 22 & 28.9 & $2.34(0.90-6.05)$ & 46 & 60.5 & $2.60(1.09-6.21)$ & \\
\hline Fall Event & & & & & & & 0.012 \\
\hline No & 41 & 19.2 & 1 & 132 & 61.7 & 1 & \\
\hline Yes & 26 & 36.6 & $2.88(1.20-6.91)$ & 36 & 50.7 & $1.24(0.55-2.79)$ & \\
\hline Number of chronic diseases & & & & & & & 0.044 \\
\hline None & 13 & 22.4 & 1 & 30 & 51.7 & 1 & \\
\hline One & 17 & 17.5 & $1.03(0.38-2.77)$ & 61 & 62.9 & $1.60(0.71-3.59)$ & \\
\hline Two or more & 37 & 31.1 & $3.04(1.16-7.99)$ & 68 & 57.1 & $2.42(1.04-5.65)$ & \\
\hline Functional capacity & & & & & & & $<0.001$ \\
\hline Independent & 12 & 9.5 & 1 & 79 & 62.7 & 1 & \\
\hline $\begin{array}{l}\text { Dependent in the Instrumental Activities } \\
\text { of Daily Living (IADL) }\end{array}$ & 37 & 31.4 & $9.81(3.83-25.10)$ & 70 & 59.3 & $2.81(1.33-5.96)$ & \\
\hline $\begin{array}{l}\text { Dependent in the Basic Activities of Daily } \\
\text { Living (BADL) and Instrumental Activities } \\
\text { of Daily Living (IADL) }\end{array}$ & 16 & 43.2 & $15.55(3.84-62.86)$ & 18 & 48.6 & 2.65(0.73-9.61) & \\
\hline Use of medication & & & & & & & 0.002 \\
\hline Up to one & 18 & 15.9 & 1 & 66 & 58.4 & 1 & \\
\hline Two or more & 50 & 28.9 & $3.83(1.76-8.35)$ & 102 & 59.0 & $2.13(1.12-4.05)$ & \\
\hline Self-perceived health & & & & & & & 0.005 \\
\hline Positive & 18 & 15.7 & 1 & 68 & 59.1 & 1 & \\
\hline Negative & 46 & 27.7 & $3.52(1.61-7.71)$ & 99 & 59.6 & $2.01(1.05-3.81)$ & \\
\hline Cognitive State & & & & & & & 0.004 \\
\hline Uncompromised & 32 & 17.4 & 1 & 111 & 60.3 & 1 & \\
\hline Compromised & 29 & 31.2 & $4.12(1.71-9.94)$ & 55 & 59.1 & $2.25(1.02-4.97)$ & \\
\hline
\end{tabular}


A significant association was found in the crude analysis for the variables: female gender $(p=0.002)$, age group $(p<0.001)$, knows how to read and write a message $(p=0.029)$, hospitalization in the previous year $(p=0.003)$, BMI $(p=0.006)$, fall event $(p=0.012)$, number of chronic diseases $(p=0.044)$, functional capacity $(p<0.001)$, medication use $(p=0.002)$, self-perceived health $(p=0.005)$ and cognitive status $(p=0.004)$.

Table 2 presents the adjusted hierarchical analysis, through multinomial logistic regression, of the association between the independent variables that obtained significance, and the classification of the frailty phenotype.

Table 2 - Final multiple multinomial logistic regression model of the association between pre-frailty and frailty and the independent variables of the study. Lafaiete Coutinho, BA, Brazil, 2011

\begin{tabular}{|c|c|c|c|c|c|}
\hline \multirow{2}{*}{ Blocks } & \multirow{2}{*}{ Variable } & Frail & \multirow{2}{*}{$p$-value } & \multirow{2}{*}{$\begin{array}{c}\text { Pre-frail } \\
\text { OR }_{\text {Adjusted }}(\mathrm{Cl} \mathrm{95 \% )}\end{array}$} & \multirow{2}{*}{$p$-value } \\
\hline & & OR $_{\text {Adjusted }}(\mathrm{Cl} 95 \%)$ & & & \\
\hline \multirow[t]{7}{*}{ A } & Gender & & & & \\
\hline & Male & 1 & & 1 & \\
\hline & Female & $2.39(1.08-5.28)$ & 0.031 & $3.21(1.63-6.31)$ & 0.001 \\
\hline & Age group & & & & \\
\hline & $60-69$ years & 1 & & 1 & \\
\hline & $70-79$ years & $1.76(0.71-4.34)$ & 0.216 & $1.41(0.69-2.86)$ & 0.336 \\
\hline & $\geq 80$ years & $10.75(3.46-33.39)$ & $<0.001$ & $3.04(1.06-8.68)$ & 0.037 \\
\hline \multirow[t]{7}{*}{ C } & Hospitalization in the previous year & & & & \\
\hline & No & 1 & & 1 & \\
\hline & One or more times & $3.19(1.10-9.27)$ & 0.033 & $1.62(0.63-4.17)$ & 0.313 \\
\hline & \multicolumn{5}{|l|}{ Body Mass Index } \\
\hline & Appropriate & 1 & & 1 & \\
\hline & Overweight & $0.50(0.15-1.63)$ & 0.255 & $1.89(0.80-4.43)$ & 0.143 \\
\hline & Underweight & $2.40(0.77-7.42)$ & 0.127 & $3.21(1.25-8.23)$ & 0.015 \\
\hline & \multicolumn{5}{|l|}{ Fall Event } \\
\hline & No & 1 & & 1 & \\
\hline & Yes & $2.32(0.80-6.72)$ & 0.120 & $0.90(0.36-2.20)$ & 0.821 \\
\hline & \multicolumn{5}{|l|}{ Functional capacity } \\
\hline & Independent & 1 & & 1 & \\
\hline & $\begin{array}{l}\text { Dependent in the Instrumental } \\
\text { Activities of Daily Living (IADL) }\end{array}$ & $6.60(2.32-18.72)$ & $<0.001$ & $1.97(0.88-4.38)$ & 0.097 \\
\hline & $\begin{array}{l}\text { Dependent in the Basic Activities of } \\
\text { Daily Living (BADL) and Instrumental } \\
\text { Activities of Daily Living (IADL) }\end{array}$ & $8.99(1.84-43.78)$ & 0.007 & $1.63(0.41-6.50)$ & 0.484 \\
\hline & \multicolumn{5}{|l|}{ Self-perceived health } \\
\hline & Positive & 1 & & 1 & \\
\hline & Negative & $3.49(1.40-8.69)$ & 0.007 & $1.78(0.89-3.57)$ & 0.102 \\
\hline
\end{tabular}

In the first step the variables of the sociodemographic block were analyzed, and the variables that remained associated with the frail stage were: female gender $(p=0.031)$ and age group $\geq 80$ years $(p<0.001)$ and, with the pre-frail stage, also female gender $(p=0.037)$ and age group $\geq 80$ years $(p=0.001)$.

In the second step the variables of the health conditions block were included and those that continued to be associated with the frail classification were: hospitalization in the previous year, one or more times $(p=0.033)$, functional capacity for both dependent in the IADL $(p<0.001)$, as well as in the BADL and IADL $(p=0.007)$, and also self-perceived negative health $(p=0.007)$. Only the underweight BMI variable $(p=0.015)$ remained associated with the pre-frail classification.

The variables related to behavioral aspects, i.e., consumption of alcoholic beverages and tobacco use were not included in the adjusted model, as they did not present at least $20 \%$ statistical significance $(p \leq 0.20)$.

\section{Discussion}

In the present study $23.8 \%$ of the elderly people were frail, $58.7 \%$ pre-frail, and $17.5 \%$ non-frail. The 
frailty prevalence values were higher when compared to international studies ${ }^{(16)}$. The explanation for the wide variation in the prevalence of frailty in the elderly is probably related to socioeconomic differences among the elderly people studied, as well as the methodological differences in the use of some instruments that differ from those that compose the items used ${ }^{(16)}$.

In the present study women had a higher prevalence in both the pre-frail and frail categories, corroborating other studies that indicated that elderly women are frailer than elderly men, and presented a frailty prevalence of over $13 \%$ for the men and $17 \%$ for the women. Over three years, the women had twice the pre-frailty incidence rates compared to the men ${ }^{(17)}$.

In a study conducted in Taiwan, which estimated the prevalence of frailty and identified factors associated with frailty, from the data of the Survey of Health and Living Status of the Elderly, it was found that the prevalence of frailty increased with age and was higher in women ${ }^{(18)}$.

Longevity is another aspect that should be taken into consideration. A national study, which is part of the multicentric project Frailty in Elderly Brazilians (Fibra), analyzed prevalence characteristics and associated factors related to frailty and, of the sociodemographic variables included in the model, only age was associated, even when adjusted for the other variables, thus demonstrating the influence of the aging process on the emergence of frailty ${ }^{(19)}$.

Weight loss has been reported to be important information related to the prediction of frailty. However, its participation in the phenomenon is still unclear, considering that weight loss does not precisely represent muscle loss, and a simultaneous increase in fat mass could mask the real estimate(20).

The studies that have investigated the association between the BMI and frailty are still inconclusive. Some have shown that pre-frail and frail elderly men presented lower BMI values and that the prevalence of frailty is slightly higher in normal and underweight men(20). Others, however, have reported an association of increased BMI values with the frail situation, mainly observed in frail elderly women(21).

The findings of the present study were consistent with the results of the study in which five Latin American and Caribbean cities were investigated, including São Paulo, Brazil, which verified that higher BMI values for women were related to a greater probability of frailty ${ }^{(9)}$.
The observation of the association between dependence in performing instrumental and basic activities and frailty is presented in national and international studies, demonstrating the degree of injury that this impairment generates in the elderly, by directly limiting them in their autonomy, resulting in a decrease in the quality of life ${ }^{(1)}$. The data obtained are consistent with the literature in that, after adjustment, an association between the BADL, IADL and frailty was also found ${ }^{(18)}$.

However, it is critical to know how the process of functional disability takes place and its relationship to frailty, therefore important adverse factors are interrelated to the two events, such as fatigue, low levels of physical activity and decreased muscle strength, which have been suggested as predictors for functional disability(22).

In this study, self-perceived health was associated with being frail, corroborating other findings(18). There are suggestions in the literature that this issue is influenced by the life trajectory and the experiences of the elderly people and the way they deal with adverse situations ${ }^{(1)}$, and overcoming these situations has been sustained by the theory that proposes the relationship between resilience in the elderly and frailty ${ }^{(23)}$.

Some limitations of the study are that this research is characterized as a cross-sectional type study, in which there is no possibility of establishing cause and effect, and that some of the instruments used required subjective or self-reported information, which may lead to memory bias. Longitudinal studies and the use of more objective instruments are needed to make the inferences about the predictive indicators of frailty more robust.

\section{Conclusion}

The prevalence of pre-frailty and frailty was $58.7 \%$ and $23.8 \%$, respectively. The evidence presented in this study showed that the state of pre-frailty was associated with gender, age group and BMI. While the state of frailty was associated with gender, age group, hospitalization, functional capacity and self-perceived health. There were more variables associated with the frailty condition, which reinforces the concept of a multifactorial clinical syndrome that may result in the loss of functionality. Furthermore, it is worth mentioning once again that the high prevalence of elderly people in the pre-frail condition constitutes 
important information, considering the possibility of deterioration and becoming frail over a short period, which will result in more care and spending on the health of these elderly people.

Therefore, the results published on the subject should serve to guide and improve the healthcare policies for the elderly, as well as assist the professionals involved in their care, whose purpose should be to prevent deterioration and its consequences, and the development of the preliminary stages of frailty into an advanced situation.

\section{References}

1. Fried LP, Tangen CM, Walston J, Newman AB, Hirsh C, Gottdiener J, et al. Frailty in older adults. J GerontolA Biol Sci Med Sci. 2001;56:M146-57.

2. Wong $\mathrm{CH}$, Weiss $\mathrm{D}$, Sourial N, Karunananthan $\mathrm{S}$, Quail JM, Wolfson C, et al. Frailty and its association with disability and comorbidity in a community-dwelling sample of seniors in Montreal: a cross-sectional study. Aging Clin Exp Res. 2010;22:54-62.

3. Xue QL. The frailty syndrome: definition and natural history. Clin Geriatr Med. 2011;27(1):1-15.

4. Veras R. Envelhecimento populacional contemporâneo: demandas, desafios e inovações. Rev Saúde Pública. 2009;43(3):548-54.

5. Albala $C$, Lebrão ML, León Díaz EM, Ham-Chande $R$, Hennis A, Palloni A, et al. Encuesta Salud, Bienestar y Envejecimiento (SABE): metodología de la encuesta y perfil de la población estudiada. Rev Panam Salud Publica. 2005;17(5/6):307-22.

6. Craig $C L$, Marshall AL, Sjöström M, Bauman AE, Booth $M L$, Ainsworth $B E$, et al. International physical activity questionnaire: 12-country reliability and validity. Med Sci Sports Exerc. 2003;35(8):1381-95.

7. Benedetti TRB, Mazo GZ, Barros MVG. Aplicação do questionário internacional de atividades físicas (IPAQ) para avaliação do nível de atividades físicas de mulheres idosas: validade concorrente e reprodutibilidade testereteste. Rev Bras Ciênc Mov. 2004;12:25-34.

8. Almeida OP, Almeida SA. Confiabilidade da versão brasileira da escala de depressão em geriatria (GDS) versão reduzida. Arq Neuropsiquiatr. $1999 ; 57(2 B): 421-6$.

9. Alvarado BE, Zunzunegui MV, Be 'Land F, Bamvita JM. Life course social and health conditions linked to Frailty in Latin American Older Men and Women. J Gerontol A Sci Med Sci. 2008;63(12):1399-406.

10. American Academy of Family Physicians. American
Dietetic Association. National Council on the Aging. Nutrition screening $e$ intervention resources for healthcare professionals working with older adults. Nutrition Screening Initiative [Internet]. Washington: American Dietetic Association; 2002 [acesso 21 jul 2011]. Disponível em: www.eatright.org

11. Katz S, Ford AB, Moskowitz RW, Jackson BA, Jaffe MW. Studies of illness in the aged. The index of ADL: a standardized measure of biological and psychosocial function. JAMA. 1963; 185(12):914-9.

12. Lawton MP, Brody EM. Assesment of older people: selfmaintaining and instrumental activities of daily living. Gerontologist. 1969;9(3):179-86.

13. Icaza MC, Albala C. Projeto SABE. Minimental State Examination (MMSE) del estudio de dementia en Chile: análisis estatístico. Brasília: OPAS; 1999.

14. Pfeffer RI, Kurosaki TT, Harrah CH Jr, Chance JM, Filos S. Measurement of functional activities in older adults in the community. J Gerontol. 1982;37(3):323-9. 15. Victora CG, Huttly SR, Fuchs SC, Olinto MTA. The role of conceptual frameworks in epidemiological analysis: a hierarchical approach. Int J Epidemiol. 1997;26:224-7.

16. Tribess S, Oliveira RJ. Síndrome da fragilidade biológica em idosos: revisão sistemática. Rev Salud Pública. 2011;13(5):853-64.

17. Peterson MJ, Giuliani C, Morye MC, Pierper CF, Evenson KR, Mercer $\mathrm{V}$, et al. Physical activity as a preventative factor for frailty: the health, aging, and body composition study. J Gerontol A Biol Sci Med Sci. 2009;64(1):61-8.

18. Chen CY, Wu SC, Chen LJ, Lue BH. The prevalence of subjective frailty and factors associated with frailty in Taiwan. Arch Gerontol Geriatr. 2010;50(Suppl 1): S43-7.

19. Sousa AC, Dias RC, Maciel AC, Guerra RO. Frailty syndrome and associated factors in community-dwelling elderly in Northeast Brazil. Arch Gerontol Geriatr. 2012;54:e95-e101.

20. Cawthon PM, Marshall LM, Michael Y, Dam TT, Ensrud KE, Barrett-Connor $\mathrm{E}$, et al. Frailty in older men: prevalence, progression, and relationship with mortality. J Am Geriatr Soc. 2007;55(8):1216-23.

21. Blaum CS, Xue QL, Michelon E, Semba R, Fried LP. The association between obesity and the frailty syndrome in older women: the Women's Health and Aging Studies. J Am Geriatr Soc. 2005;53(6):927-34.

22. Avlund K. Fatigue in older adults: an early indicator of the aging process? Aging Clin Exp Res. $2010 ; 22: 100-15$. 
23. Varadhan R, Seplaki CL, Xue QL, Bandeen-Roche K, Fried LP. Stimulus-response paradigm for characterizing the loss of resilience in homeostatic regulation associated with frailty. Mech Ageing Dev. 2008;129:666-70. 